\title{
Vocational rehabilitation in early psychosis: cluster randomised trial
}

\author{
Tom Craig, Geoff Shepherd, Miles Rinaldi, Jo Smith, Sarah Carr, Fay Preston and Swaran Singh
}

\section{Background}

Individual placement and support (IPS) is effective in helping patients return to work but is poorly implemented because of clinical ambivalence and fears of relapse.

\section{Aims}

To assess whether a motivational intervention (motivational interviewing) directed at clinical staff to address ambivalence about employment improved patients' occupational outcomes.

\section{Method}

Two of four early intervention teams that already provided IPS were randomised to receive motivational interviewing training for clinicians, focused on attitudinal barriers to employment. The trial was registered with the International Standard Randomised Controlled Trial Register (ISRCTN71943786)

\section{Results}

Of 300 eligible participants, 159 consented to the research.
Occupational outcomes were obtained for 134 patients (85\%) at 12-month follow-up. More patients in the intervention teams than in the IPS-only teams achieved employment by 12 months (29/68 v. 12/66). A random effects logistic regression accounting for clustering by care coordinator, and adjusted for participants' gender, ethnicity, educational and employment history and clinical status scores, confirmed superiority of the intervention (odds ratio $=4.3,95 \% \mathrm{Cl} 1.5-16.6$ ).

\section{Conclusions}

Employment outcomes were enhanced by addressing clinicians' ambivalence about their patients returning to work.

\section{Declaration of interest}

J.S. and M.R. are independent consultants to the Catalyst IPS programme with Jannsen Cilag, UK. T.C. has spoken about employment at an educational event organised by Roche.
Unemployment is common in young people recovering from a first episode of psychosis, ${ }^{1-3}$ although many still aspire to return to paid employment. ${ }^{4-6}$ Of the various methods of vocational rehabilitation, the strongest evidence base is found for individual placement and support (IPS), which involves rapid job search combined with minimal pre-vocational preparation and ongoing support. ${ }^{7,8}$ However, the majority of studies have involved highly motivated participants, who signed up not only for employment but also to take part in research, ${ }^{9}$ and translation into routine clinical care has often proved difficult, ${ }^{10}$ frequently because of the attitudes of key clinicians who discourage a return to work through a fear that the demands of employment might precipitate relapse. ${ }^{11,12}$ We therefore aimed to determine the feasibility, acceptability and effectiveness of combining IPS with training staff in early intervention teams in 'motivational interviewing' strategies. These aim to address anxiety about employment 'through a directive, client centred counselling style . . . helping clients to explore and resolve ambivalence' (p.326). ${ }^{13}$ There are over 150 controlled trials demonstrating the value of motivational interviewing in a variety of settings in health and social care,${ }^{14}$ and these techniques are now beginning to be employed in mental health services, particularly to address motivational conflicts with regard to medication adherence. ${ }^{15,16}$ Our primary hypothesis was that at 12 months a greater percentage of young people treated by early intervention teams that had staff trained in both IPS and motivational interviewing would achieve open employment compared with those in teams providing IPS only. A secondary hypothesis was that participants from the teams using motivational interviewing who found employment would have longer job tenure.

\section{Method}

A pragmatic, cluster-randomised controlled trial was conducted in England with four early intervention teams, two in south London and two in the Midlands. The study, entitled Enhancing Delivery and Outcomes of Vocational Rehabilitation (ENDEAVOR), was registered with the International Standard Randomised Controlled Trial Number Register (ISRCTN71943786). All the participating teams included a trained vocational specialist who provided supported employment services using the IPS model. Two of the teams (one in London and one in the Midlands) were randomised to receive additional training in motivational techniques aimed at addressing staff concerns about the value and risks of a return to open (i.e. competitive) employment. A cluster design was chosen in preference to randomisation at an individual level to avoid 'seepage' from the experimental conditions into the control arms of the study. It was also impractical to attempt to employ two vocational workers in each team with only one trained in the motivational interviewing techniques. Finally, we wished to apply the motivational training to the whole clinical team on the basis that encouragement to seek and retain employment needs to be provided by the clinicians, who have the most contact with patients, and not just by the employment specialists who are already committed to employment goals. The focus of the evaluation was on the occupational outcomes of the people receiving treatment in these services.

\section{Clinical teams}

The characteristics of the four teams were as follows. London 1 served an inner-city area with an average index of deprivation score of 34.9 (a high score, ranking the area 19 out of the 354 boroughs in England) and a 10\% unemployment rate at the start of the study. London 2 served a mixed urban/suburban population with an average index of deprivation of 20.3 (ranking 144 out of 354 boroughs) and an average unemployment rate of $5 \%$. Midlands 1 served an inner-city population with an average index of deprivation of 38.7 (ranked 10 out of 354 local authorities in England) with approximately $8 \%$ of the 
working-age population unemployed at the start of the study. Midlands 2 served a mixed urban and rural economy with a significant rural population; although not regarded as having high levels of deprivation overall (average index of deprivation 18.0, ranked 162 out of 354 boroughs nationally) it was within the lowest $20 \%$, with some extremely deprived rural areas, and at the time of the study it had an unemployment rate of $7 \%$ among people aged 18-24 years. The four early intervention teams were similar in terms of the numbers and professional disciplines of staff and in the number of cases under their care (range 171-207). Patient care in these teams was organised through a care coordination system such that each patient had a named clinician ('care coordinator') who provided direct care and worked alongside other members of the team who might be providing additional therapeutic interventions such as medication or a specific psychological intervention.

\section{Participants}

Patients were eligible for inclusion in the study if they were aged 18-35 years, not currently in work (i.e. part-time or whole-time mainstream employment) or full-time education but with the legal right to employment in England, and expected to remain under the care of the early intervention service for at least the subsequent 12 months (the early intervention services in this study provided care for a period of 2-3 years following a first episode, at the end of which patients needing continued specialist supervision were transferred to other non-early intervention community mental health teams). They also needed to be capable of giving written informed consent to the research. There was no requirement that they be particularly motivated to return to work or study.

\section{Interventions}

To minimise variation in practice regarding vocational interventions, the vocational specialists in the teams were trained to deliver IPS with fidelity to the published research instruments. ${ }^{17}$ They were also provided with written practice guidelines and support by M.R. who had previous experience with a fidelity-based approach in a large international trial. ${ }^{18}$ Care coordinators in the two teams that were randomised to receive the motivational interviewing training were provided with this by recognised experts. The training comprised a 3-day course, followed by two further sessions over the next 3 months. A 2-day 'refresher' course was provided in the second year of recruitment. The training aimed to provide clinicians with a clear understanding of issues such as intrinsic motivation, ambivalence and readiness to change, as well as how to influence conversations, recognise appropriate times to use motivational interviewing and feel confident in the use of motivational interviewing in everyday practice. Training days consisted of brief didactic work, discussion, role-play and recorded demonstrations. Later sessions focused on discussion of cases. Although the training was directed at care coordinators and vocational specialists, other clinical staff in the teams were encouraged to take part. Research ethics approval was obtained through the Charing Cross research ethics committee.

\section{Measures}

The primary outcome was the proportion of young people in open paid employment at 12-month follow-up. Open employment was defined as having a job paying at least the minimum wage in a mainstream setting and not specifically for people with disability. Tenure was also recorded (number of days in this employment).
Information on occupational activity was obtained from the young people themselves, from the clinical record and in two instances from family sources (where consent was given). Baseline information was also collected relating to sociodemographic variables and previous educational and employment history. All participants were asked to score their desire to return to work and their belief that this could be achieved in the near future separately on Likert scales scored from 0 (no desire/impossible) to 10 (maximum desire/strong conviction they would succeed). Clinical status was recorded at entry to the study and at follow-up using the Positive and Negative Syndrome Scale (PANSS) and the Global Assessment of Functioning (GAF). ${ }^{19,20}$ It was not possible to maintain masking to team allocation. This bias was mitigated by the use of the factual record of employment or education, cross-checked with other available records.

\section{Statistical analysis}

Data were analysed using SPSS for Windows PC version 17 and Stata version 11. In addition to comparisons across the two arms of the study, data were also compared in terms of those followed up $v$. those who left the study for the total sample and by treatment arm. Chi-squared tests with odds ratios were used to compare proportions and $t$-tests to compare means unless the data were highly skewed, in which case non-parametric tests were used. Random effects logistic regression models, taking account of clustering by care coordinator, were fitted including potential confounding variables: age, gender, ethnicity, best prior educational level, previous employment and clinical status (total PANSS and GAF scores).

\section{Results}

Teams were recruited and baseline motivational training completed before recruitment of patients. Training sessions were staggered to ensure maximum attendance. Attendance at baseline sessions was good, particularly by the care coordinators who were the primary target of the training and who had most contact with patients in the early intervention teams. The employment specialist, team leader and all care coordinators in the two motivational interviewing teams attended the baseline training, as did the social worker in the Midlands team. Attendance was less good for clinical psychologists and psychiatrists, with just one of three clinical psychologists and one trainee psychiatrist attending any session. Booster sessions were attended by the 2 employment specialists and by 23 of a possible total of 28 care coordinators. Young people under the care of the early intervention teams were recruited between June 2009 and April 2011. The flow of participants through the study is shown in Fig. 1.

Of the 675 young people on the case-load of the four teams, $375(55 \%)$ did not meet criteria for inclusion in the study. Of the latter, 100 were already in employment and 150 had been or were due to be transferred or discharged from the early intervention service within 12 months. A small number could not give informed consent or were not available (e.g. in prison or abroad). Of the remaining 300 eligible patients, 160 consented but 1 withdrew before completing the baseline assessment and asked that all his data be removed. This left 159 participants who completed baseline assessments. There was no significant difference between the two arms on baseline variables. Although we did not recruit on the basis of a predetermined threshold for a desire to return to work, participants in all teams expressed a wish to work (mean score 7.8, s.d. $=2.1$, from a total possible score of 10), although most also thought they would be unlikely to achieve this ambition in the near future (mean score 3.9, 


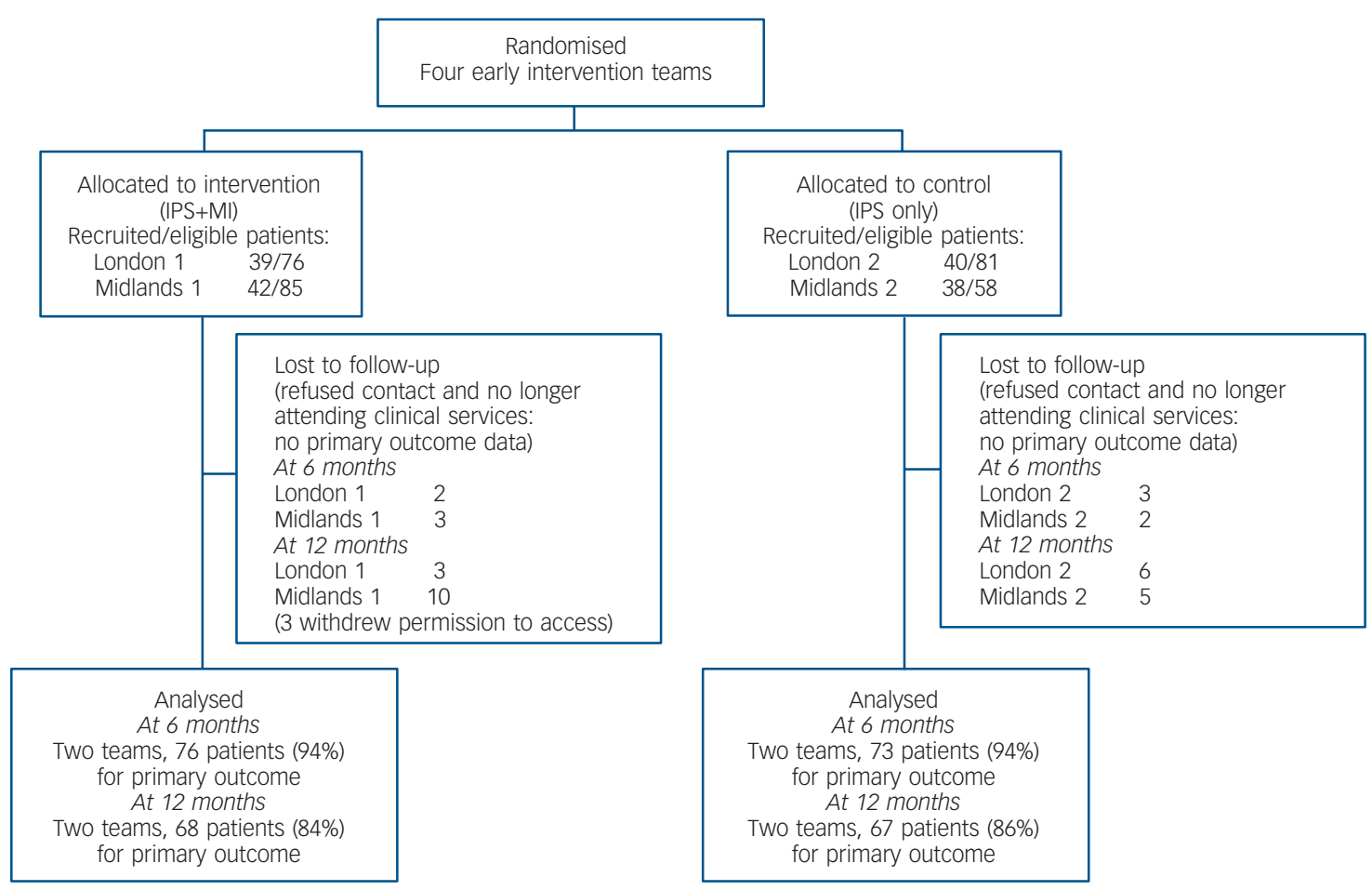

Fig. 1 Study profile. IPS, individual placement and support; MI, motivational interviewing.

s.d. $=2.0$, from a possible 10 ). There was no statistically significant difference in the distribution of these scores between patients in the different teams or between those who completed or were lost to follow-up.

Ten participants were completely lost to both the clinical team and research staff at the 6-month follow-up point. This had increased to 24 by the 12 -month point. All had discontinued contact with the clinical team and could not be traced or refused contact with the researchers. None had been in employment or education when last seen by the clinical service. There was no significant difference in demographic or clinical variables between those who were and were not lost to follow-up at 6 months or 12 months (data available from the author on request).

Table 1 shows baseline sociodemographic and clinical variables across all four teams. It is apparent that there were significant differences between the teams, with the majority of Black African and Black Caribbean patients in the London teams, the majority of Asians in one Midlands team and very few from ethnic minority populations in the second Midlands team.

\section{Process data}

Implementation of IPS was assessed by service-user consultants who were independent of services and the research team, using version 8 of the IPS Fidelity Scale from the Dartmouth IPS Supported Employment Center. ${ }^{17}$ Scores on this measure for the four teams ranged from 'good' (both London teams and the intervention team in the Midlands had scores of 111 to 114 out of a possible total of 125) to 'exemplary' (the control team in the Midlands with a score of 116). All four teams were rated as

\begin{tabular}{|c|c|c|c|c|c|c|}
\hline & \multicolumn{2}{|c|}{ Intervention: IPS+MI } & \multicolumn{2}{|c|}{ Control: IPS only } & \multicolumn{2}{|c|}{ Comparison } \\
\hline & $\begin{array}{l}\text { Midlands } 1 \\
\quad(n=42)\end{array}$ & $\begin{array}{l}\text { London } 1 \\
(n=39)\end{array}$ & $\begin{array}{l}\text { London } 2 \\
(n=40)\end{array}$ & $\begin{array}{c}\text { Midlands } 2 \\
\quad(n=38)\end{array}$ & $\begin{array}{c}\text { Across teams } \\
P\end{array}$ & $\begin{array}{l}\text { Between intervention } \\
\text { and control, } P\end{array}$ \\
\hline Male, $n(\%)$ & $34(81)$ & $28(72)$ & $25(63)$ & $29(76)$ & 0.28 & 0.29 \\
\hline \multicolumn{7}{|l|}{ Ethnicity, $n$ (\%) } \\
\hline White & $22(52)$ & $20(51)$ & $13(33)$ & $35(92)$ & 0.003 & 0.007 \\
\hline Black & $10(24)$ & $11(28)$ & $24(60)$ & $2(5)$ & & \\
\hline Asian & $10(24)$ & $8(21)$ & $3(8)$ & $1(3)$ & & \\
\hline Ever worked, $n(\%)$ & $35(83)$ & $26(67)$ & $28(70)$ & $28(73)$ & 0.35 & 0.61 \\
\hline Worked since unwell, $n(\%)$ & $11(26)$ & $14(36)$ & $13(33)$ & $16(42)$ & 0.51 & 0.43 \\
\hline Age, years: mean (s.d.) & $23(4.2)$ & $25(4.2)$ & $24(4.7)$ & $24(3.7)$ & 0.46 & 0.73 \\
\hline Work importance score, mean (s.d.) & $7.2(2.7)$ & $7.6(2.0)$ & $8.4(2.1)$ & $7.2(2.3)$ & 0.06 & 0.18 \\
\hline Work likelihood score, mean (s.d.) & $3.9(2.3)$ & $3.9(2.2)$ & $4.2(2.0)$ & $3.7(1.7)$ & 0.79 & 0.19 \\
\hline PANSS total score, mean (s.d.) & $50.1(20.6)$ & $31.6(16.9)$ & $35.1(16.6)$ & $45.6(20.8)$ & 0.01 & 0.61 \\
\hline GAF score, mean (s.d.) & $70.6(13.5)$ & $68.1(15.1)$ & $67.9(16.6)$ & $68.2(15.1)$ & 0.80 & 0.71 \\
\hline
\end{tabular}




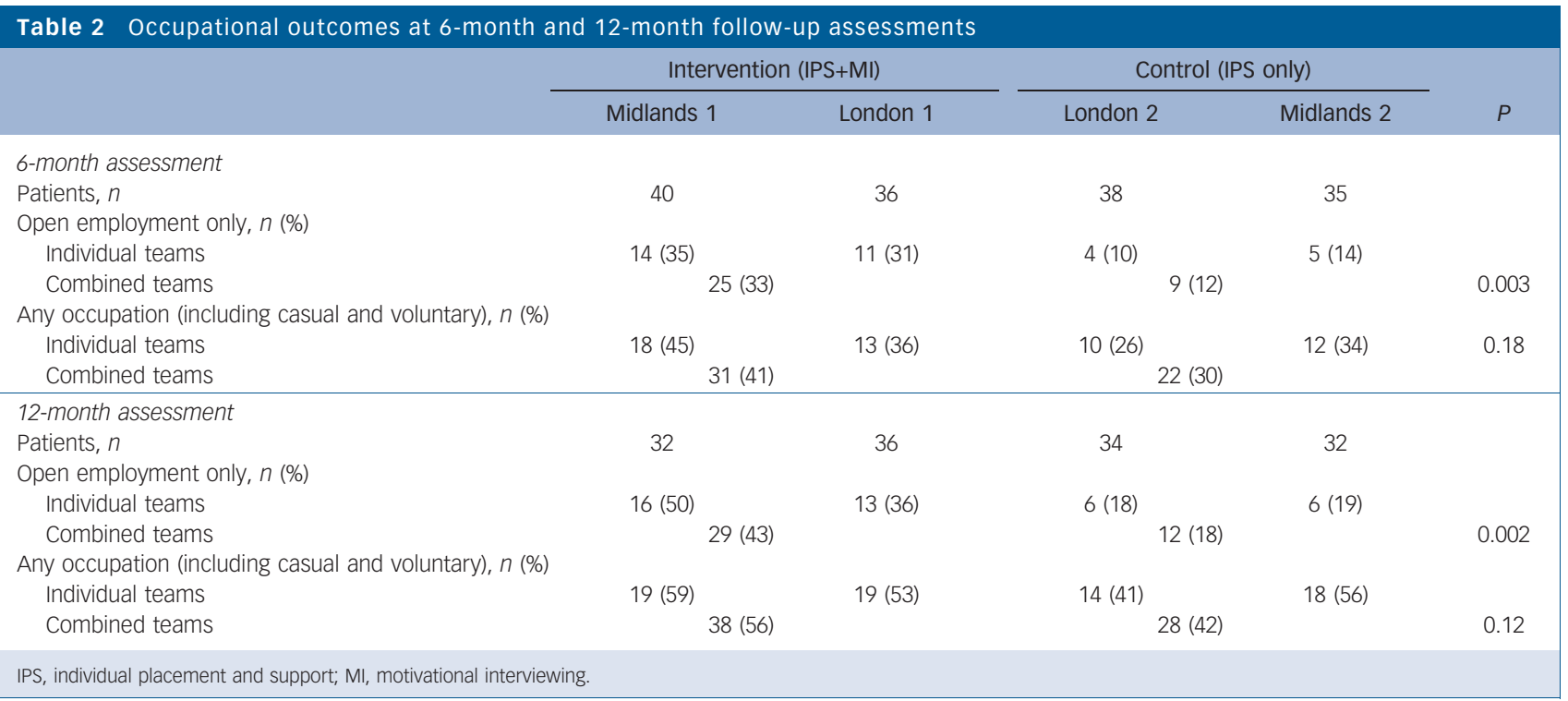

having IPS fully integrated with the mental health team. However, two teams - one in the intervention arm and one in the control arm - experienced gaps in the availability of IPS specialists when staff moved on or were absent through illness (in both instances over comparable 6-month periods between December 2009 and June 2010).

\section{Occupational outcomes}

Table 2 shows the employment outcomes at the 6-month and 12-month follow-up points. It is apparent that the majority of those in open employment at the 12-month assessment had already returned to work by 6 months. By the 12-month follow-up, of the 134 young people for whom employment information was available, only $41(30 \%)$ were recorded as having worked in a job that met the criteria for open employment. Of these, 29 were patients of the teams that were provided with motivational training (odds ratio $(\mathrm{OR})=3.5,95 \%$ CI 1.5-8.1). Sensitivity analyses were carried out on these 12-month outcomes. Regardless of the direction of this analysis, patients in the combined intervention teams were more likely than those in the control teams to have attained open employment. If all missing patients were considered to be employed then the combined intervention showed $31 / 81 v$. control $21 / 78\left(\chi^{2}=3.97\right.$, d.f. $\left.=1, P=0.046\right)$; if all missing were considered to be unemployed then the combined intervention showed $26 / 81 v$. control $11 / 78\left(\chi^{2}=7.21\right.$, d.f. $=1$, $P=0.007)$. Finally, a random effects logistic regression taking account of clustering by care coordinator and adjusted for gender, ethnicity, educational attainment, employment history and PANSS and GAF scores confirmed significant independent effects for the combined motivational interviewing plus IPS intervention $(\mathrm{OR}=4.3,95 \% \mathrm{CI} 1.5-16.6)$ and level of prior educational attainment $(\mathrm{OR}=1.8,95 \%$ CI 1.01-3.5).

For those in employment, the hours worked per week were similar in the combined intervention group (median $30 \mathrm{~h}$, interquartile range 19.0-37.5) and the control group (median $37.5 \mathrm{~h}$, interquartile range (IQR) 16.0-37.5; Mann-Whitney $Z=-0.231$, $P=0.82$ ). There was also no significant difference between the groups in terms of the length of time the employment lasted (intervention median 65 days, IQR 13-168, v. control median 117 days, IQR 30-168; Mann-Whitney $Z=-0.993, P=0.32$ ). The majority of jobs were entry-level posts such as manual worker $(30 \%)$ or sales assistant $(42 \%)$. Other occupations included skilled trades $(24 \%)$ and a few in professional occupations (4\%). If only those in work at the day of interview were included, there was still an advantage for the combined intervention group (26/68 v. 10/66; $\chi^{2}=8.79$, d.f. $\left.=1, P=0.003\right)$.

Although focused on our primary outcome of paid employment, this analysis underestimates the total occupational activity across all the teams. Thus, a number of patients worked in unpaid voluntary positions and others undertook short-term 'cash in hand' jobs such as helping a relative who was a selfemployed gardener or writing an article for a magazine. Including these voluntary and cash-in-hand jobs effectively eliminated the difference in occupational outcomes between the teams (Table 2). The voluntary posts included working part-time in a charity shop, as a stage-hand for a rock concert, and work experience posts specially created by the local mental health services. Voluntary posts are often said to be stepping stones to employment, but this seldom proved to be the case, with only two young people moving to open employment from their voluntary activity over the course of the study. An important occupational outcome for many young people who develop a psychotic illness in their late teens and early adulthood is the return to college to complete studies and obtain formal qualifications. More of the participants in the combined intervention teams returned to formal education $(28 \%, n=21)$ compared with the control condition $(14 \%, n=10)$ over the initial 6 months of the study (OR $=2.4,95 \%$ CI 1.1-5.6). This included returning to complete higher education courses, undertaking vocational training (leading to a recognised qualification) and, for two young people, a return to paid employment that included an educational component leading to a professional qualification (e.g. accountancy). Nearly half of the participants in the intervention teams and a quarter of those in the comparison arm by the 12-month follow-up point were engaged in either open employment or formal education $(\mathrm{OR}=3.6,95 \%$ CI 1.9-7.2). This included 13 individuals who engaged in both activities over the course of the year.

\section{Discussion}

The majority of young people who experience a first episode of psychosis do so at a critical juncture in their lives, often while in their first employment. This disruption contributes to the rapid emergence of disabilities which can blight their subsequent life over many years. ${ }^{21}$ Although many of these young people have 
the same aspirations as their healthy peers, to have a well-paid job, a home and to be self-sufficient, ${ }^{4-6}$ the reality is that this ideal is achieved by relatively few, and (in the UK at least) it seems this motivation may be lost as patients become embedded in services. $^{22-24}$ There are several reasons for this, but undoubtedly one of the most important is the lack of encouragement and the low expectations conveyed by many professionals. There is ample evidence from both research studies and personal accounts that testify to the negative views of clinicians who are often more concerned about the impact of work-related stress on the risk of relapse, rather than the psychological, social and financial benefits associated with a rapid return to employment. ${ }^{11,12,25}$ These fears of provoking relapse are largely misplaced. There is actually more evidence that prolonged inactivity is likely to lead to the exacerbation of the range of problems associated with the 'sick role' (loss of confidence, reduced self-esteem, decreased social contact, dependence on services and welfare benefits) than there is that returning to employment increases the likelihood of relapse. ${ }^{10,26,27}$

Early intervention teams are among the few specialist mental health teams in England that have adopted the IPS approach and have vocational workers fully embedded within their teams. This study was designed to determine whether the addition of training in strategies to address the motivational conflicts (among staff and patients) about return to work would make a difference to outcomes. The results suggest that this is indeed the case and that providing clinical staff with specific training in techniques to address patients' (and their own) motivational conflicts may enhance patients' chances of moving towards competitive employment. We have also demonstrated that it is feasible to involve teams working across a broad range of socioeconomic deprivation, from inner-city areas through more affluent suburban settings and a rural location. It is also worth noting that community conditions are unlikely to account for the better outcomes in the intervention teams because deprivation and unemployment were lower in the areas served by the control teams.

\section{Study limitations}

There are, however, a number of caveats. First, we cannot be certain that the better outcomes in the intervention teams were due to any particular motivational discussion between care coordinator and the young person. The motivational interviewing training was focused on the clinicians and tackled their own ambivalence as well as providing strategies to use when discussing employment with their patients. Team-wide training and discussion are advocated as part of the preparation for the implementation of IPS, ${ }^{28}$ so it could be that the observed benefit of the intervention reflects the response to the team-wide focus on employment as an important outcome that all members of the clinical team should consider. Second, the number of young people who consented to the research represented only half of all those who met study eligibility criteria, and of those recruited a fifth were not traceable at 12 months, having disengaged from both the clinical teams and the research. Other UK-based studies of supported employment have reported similar difficulties in recruiting and maintaining participants' involvement. ${ }^{18,29}$ Third, a lower percentage achieved competitive employment than anticipated, despite all teams employing experienced IPS workers with fidelity measure scores, suggesting more than adequate implementation of the IPS model in all sites. The low employment rate is particularly striking for the comparison teams, where only $18 \%$ of participants obtained paid work in the 12-month period. It is difficult to put these data into context as there have been only two randomised controlled trials of IPS in the UK and neither included substantial numbers of young people recovering from a first episode of psychosis. Rates of employment in the IPS arms of these studies ranged between $13 \%$ and $48 \%{ }^{29,26}$ The apparently low employment rate in our study may reflect the fact that we deliberately excluded those who were already in work at the start of the study and did not select participants on the basis of a commitment to returning to work. Finally, these results also need to be considered within the overall context of the wider economic recession that was at its height at the time of the study. They may also reflect the temporary absences of employment specialists in one intervention team and one control team, although these gaps were for similar periods.

\section{Future research}

In conclusion, this study has demonstrated improved occupational outcomes when training in how to address motivational problems was added to an evidence-based approach to employment (IPS) delivered by trained vocational specialists embedded in early intervention teams. These results encourage further, more definitive, trials.

\section{Funding}

The study was funded by a grant from the National Institute for Health Research (NIHR) under its Research for Patient Benefit programme. The views expressed are those of the authors and not necessarily those of the National Health Service, the NIHR or the Department of Health.

Tom Craig, MBBS, PhD, FRPsych, Health Services and Population Research Department (HSPRD), Institute of Psychiatry, King's College London; Geoff Shepherd, BSC, MPhil, PhD, Centre for Mental Health, London; Miles Rinaldi, South West London and St George's Mental Health National Health Service (NHS) Trust, London; Jo Smith, BSC, MSc, PhD, Worcestershire Early Intervention Service, Worcestershire Health and Care NHS Trust and University of Worcester; Sarah Carr, BSC, MSC, Institute of Psychiatry, King's College London; Fay Preston, BSC, Swaran Singh, MBBS, PhD, FRCPsych, Warwick Medical School, University of Warwick, UK

Correspondence: Professor Tom K. J. Craig, HSPRD, King's College London, Institute of Psychiatry, De Crespigny Park, London SE5 8AF, UK. Email: Thomas.Craig@kcl.ac.uk

First received 16 Aug 2013, final revision 4 Mar 2014, accepted 14 Mar 2014

\section{References}

1 Rinaldi M, McNeil K, Firn M, Koletsi M, Perkins R, Singh SP. What are the benefits of evidence-based supported employment for patients with first-episode psychosis? Psychiatr Bull 2004; 28: 281-4.

2 Birchwood M, Cochrane R, Macmillan F, Copestake S, Kucharska J, Carriss M. The influence of ethnicity and family structure on relapse in first-episode schizophrenia. A comparison of Asian, Afro-Caribbean, and white patients. Br J Psychiatry 1992; 161: 783-90.

3 Marwaha S, Johnson S. Schizophrenia and employment: a review. Soc Psychiatry Psychiatr Epidemiol 2004; 39: 337-49.

4 Secker J, Grove B, Seebohm P. Challenging barriers to employment, training and education for mental health clients: the client's perspective. J Ment Health 2001; 10: 395-404

5 Parker C. First person account: landing a Mars Lander. Schizophr Bull 2001; 27: $717-8$.

6 Gioia D, Brekke JS. Knowledge and use of employment provisions of the Americans with Disabilities Act (ADA) by young adults with schizophrenia. Psychiatr Serv 2003; 54: 302-4.

7 Crowther RE, Marshall M, Bond GR, Huxley P. Helping people with severe mental illness to obtain work: systematic review. BMJ 2001; 322: 204-8.

8 Killackey E, Jackson HJ, McGorry PD. Vocational intervention in first-episode psychosis: individual placement and support $v$. treatment as usual. Br J Psychiatry 2008; 193: 114-20.

9 Drake RE, McHugo GJ, Bebout RR, Becker DR, Harris M, Bond GR, et al. A randomized clinical trial of supported employment for inner-city patients with severe mental disorders. Arch Gen Psychiatry 1999; 56: 627-33. 
10 Bond GR, Becker DR, Drake RE, Rapp CA, Meisler N, Lehman AF, et al. Implementing supported employment as an evidence-based practice. Psychiatr Serv 2001; 52: 313-22.

11 Marwaha S, Balachandra S, Johnson S. Clinicians' attitudes to the employment of people with psychosis. Soc Psychiatry Psychiatr Epidemiol 2008; 44: 349-60.

12 Rinaldi M, Miller L, Perkins R. Implementing the Individual Placement and Support (IPS) approach for people with mental health conditions in England. Int Rev Psychiatry 2010; 22: 163-72.

13 Rollnick S, Miller WR. What is motivational interviewing? Behav cog Psychother 1995; 23: 325-34.

14 Rollnick S, Miller W, Butler C. Motivational Interviewing in Health Care. Guilford, 2008

15 Kemp R, Hayward P, Applewhaite G, Everitt B, David A. Compliance therapy in psychotic patients: randomised controlled trial. BMJ 1996; 312: 345-9.

16 Barrowclough C, Haddock G, Tarrier N, Lewis SW, Moring I, O'Brien R, et al Randomized controlled trial of motivational interviewing, cognitive behavior therapy, and family intervention for patients with comorbid schizophrenia and substance use disorders. Am J Psychiatry 2001; 158: 1706-13.

17 Bond GR, Peterson AE, Becker DR, Drake RE. Validating the revised Individual Placement and Support Fidelity Scale (IPS-25). Psychiatr Serv 2012; 63: 758-63

18 Burns T, Catty J, Becker T, Drake RE, Fioritti A, Knapp M, et al. The effectiveness of supported employment for people with severe mental illness: a randomised controlled trail in six European countries. Lancet 2007; 370: 1146-52.

19 Kay SR, Fiszbein A, Opler LA. The Positive and Negative Syndrome Scale (PANSS) for schizophrenia. Schizophr Bull 1987: 13: 261-76.
20 Endicott J, Spitzer RL, Fleiss JL, Cohen J. The Global Assessment Scale: a procedure for measuring overall severity of psychiatric disturbance. Arch Gen Psychiatry 1976; 33: 766-71.

21 Birchwood M, Fiorillo A. The critical period for early intervention. Psychiatr Rehab Skills 2000; 4: 182-98.

22 Singh SP, Croudace T, Amin S, Kwiecinski R, Medley I, Jones PB, et al. Three-year outcome of first-episode psychoses in an established community psychiatric service. Br J Psychiatry 2000; 176: 210-6.

23 Garety PA, Rigg A. Early psychosis in the inner city: a survey to inform service planning. Soc Psychiatry Psychiatr Epidemiol 2001; 36: 1-8.

24 Garety PA, Craig TKJ, Dunn G, Fornells-Ambrojo M, Colbert S, Rahaman N, et al. Specialised care for early psychosis: symptoms, social functioning and patient satisfaction. Randomised controlled trial. Br J Psychiatry 2006; 188 : 37-45.

25 Rosenheck R, Leslie D, Keefe R, McEvoy J, Swartz M, Perkins D, et al. Barriers to employment for people with schizophrenia. Am J Psychiatry 2006; 163: 411-7.

26 Burns $\mathrm{T}$, Catty J, White $\mathrm{S}$, Becker $\mathrm{T}$, Koletsi M, Fioritti $\mathrm{A}$, et al. The impact of supported employment and working on clinical and social functioning: results of an international study of individual placement and support. Schizophr Bull 2009; 35: 949-58.

27 Mueser KT, Clark RE, Haines M, Drake RE, McHugo GJ, Bond GR, et al. The Hartford study of supported employment for persons with severe mental illness. J Consult Clin Psychol 2004; 72: 479-90.

28 Corrigan PW, Mueser K, Bond G, Drake RE, Solomon P. Employment and education. In Principles and Practice of Psychiatric Rehabilitation: An Empirical Approach: 195-209. Guilford, 2008.

29 Howard LM, Heslin M, Leese M, McCrone $\mathrm{P}$, Rice $\mathrm{C}$, Jarrett $\mathrm{M}$, et al Supported employment: randomised controlled trial. Br J Psychiatry 2010; 196: 404-11.

\section{poem}

\section{Suicide in the Trenches}

\section{Siegfried Sassoon}

I knew a simple soldier boy

Who grinned at life in empty joy,

Slept soundly through the lonesome dark, And whistled early with the lark.

In winter trenches, cowed and glum, With crumps and lice and lack of rum, He put a bullet through his brain.

No one spoke of him again.

You smug-faced crowds with kindling eye Who cheer when soldier lads march by, sneak home and pray you'll never know The hell where youth and laughter go.

(c) Siegfried Sassoon. Reprinted with permission. Selected by Femi Oyebode. 